\title{
Adolescent sexual aggressiveness and pornography use: A longitudinal assessment
}

Dawson, Kate; Tafro, Azra; Štulhofer, Aleksandar

Source / Izvornik: Aggressive Behavior, 2019, 45, 587 - 597

Journal article, Accepted version

Rad u časopisu, Završna verzija rukopisa prihvaćena za objavljivanje (postprint)

https://doi.org/10.1002/ab.21854

Permanent link / Trajna poveznica: https://urn.nsk.hr/urn:nbn:hr:131:016328

Rights / Prava: In copyright/Zaštićeno autorskim pravom.

Download date / Datum preuzimanja: 2023-04-26

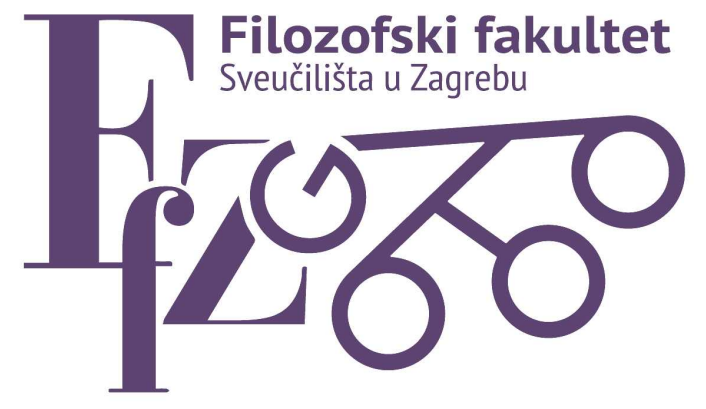

Repository / Repozitorij:

ODRAZ - open repository of the University of Zagreb Faculty of Humanities and Social Sciences
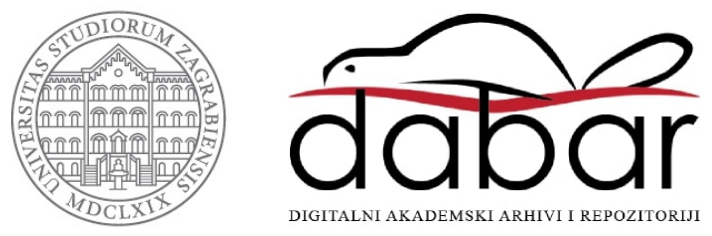
ADOLESCENT SEXUAL AGGRESSIVENESS AND PORNOGRAPHY USE: A

\title{
LONGITUDINAL ASSESSMENT
}

\author{
Kate Dawson ${ }^{1}$ \\ Azra Tafro, $\mathrm{PhD}^{2}$ \\ Aleksandar Štulhofer, $\mathrm{PhD}^{3}$ \\ ${ }^{1}$ School of Psychology, National University of Ireland, Galway, Ireland \\ ${ }^{2}$ Department of Electronics Systems and Information Processing, Faculty of Electrical \\ Engineering and Computing, University of Zagreb, Zagreb, Croatia \\ ${ }^{3}$ Department of Sociology, Faculty of Humanities and Social Sciences, University of Zagreb, \\ Zagreb, Croatia
}

\section{Correspondence to:}

Kate Dawson

Email: kate.dawson@nuigalway.ie

\section{Acknowledgements:}

This work has been fully funded by Croatian Science Foundation (grant number 9221 awarded to the last author). 


\begin{abstract}
:
The rising prevalence of (online) pornography use among, mostly male, adolescents revived social concerns regarding possible effects of pornography use on sexual aggressiveness. Given the paucity of longitudinal explorations of this link, this study focused on the following two research questions: (Q1) Is pornography use during middle to late adolescence related to male adolescents' self-reported sexual aggressiveness; and (Q2) can personality traits and characteristics that have been associated with sexual aggression account for this presumed link? Using data from a 6-wave panel sample of 594 male Croatian high-school sophomore students $\left(M_{\text {age at baseline }}=15.8\right.$ years, $\left.\mathrm{SD}=.52\right)$, latent class and latent growth curve modelling were employed to answer these questions. There was a significant baseline difference in the frequency of pornography use between participants who reported no or marginal levels of sexual aggressiveness during the period under observation (20 months) and their peers who reported substantial sexual aggressiveness, with the former reporting significantly lower initial levels of pornography use compared to the latter. Controlling for personality characteristics did not cancel this association. In addition, bullying and reported peer pressure significantly predicted initial levels of pornography use, but not its subsequent change. With the controls omitted from the analysis, a slight average increase in pornography use was observed in the first latent class. In contrast, pornography use decreased somewhat among their peers who reported sexual aggressiveness. Insights from this study can contribute to school-based sexual violence prevention programs, as well as inform recently proposed pornography literacy programs which aim to assist adolescents in navigating the increasingly sexually explicit online environment.
\end{abstract}

\title{
Key Words:
}


Adolescents, sexual aggressiveness, pornography use, longitudinal assessment 


\section{ADOLESCENT SEXUAL AGGRESSIVENESS AND PORNOGRAPHY USE: A LONGITUDINAL ASSESSMENT}

\section{INTRODUCTION}

Adolescence is a key stage in sexual development, where beliefs about appropriate sexual behaviour are formed (Fortenberry, 2014). It is well documented that many harmful behaviours manifest during adolescence, with approximately half of sexual offenders reporting their first assault during this time (Righthand, Welch, Carpenter, Young, \& Scoular, 2001). Due to its increased and unrestricted availability on the Internet, pornography use is a part of many adolescents' experience (Peter \& Valkenburg, 2016). The rising prevalence of pornography use mostly, but not exclusively, among male adolescents prompted concerns among researchers and policy makers about the impact of pornography on youth sexual socialization—particularly regarding the acquisition of sexual scripts which may increase the risk of sexual aggression (Wright, 2011; Wright \& Bae, 2016). A number of theories have been proposed to explain possible association between pornography use and sexual aggression. Many are grounded in sexual script theory (Simon \& Gagnon, 2003) and Bandura's (1978) theory of social learning, which argue that individuals may model their sexual behaviour after pornographic depictions. Others endorse the selective exposure hypothesis (D'Alessio \& Allen, 2007) and argue that preexisting preferences and specific attitudes underlie both the selection of sexualized media and sexual aggressiveness. To address these important and socially relevant issues, this study explores the association between male adolescents' pornography use and sexual aggressiveness using longitudinal design and within-person latent variable analytical approach.

\section{Pornography Use and Sexual Aggression}


The body of literature which has examined the link between pornography and sexual violence has found evidence of an effect for a small proportion of individuals. For example, longitudinal research of North American adolescents involving 6-waves of data collection showed the use of violent pornographic content, which was defined as depicting "one person physically hurting another person while doing something sexual", was associated with sexual aggression and coercion even after controlling for several other risk factors for sexual aggression (Ybarra \& Thompson, 2018). Similar results were reported by another study that found that after controlling for risk factors like non-sexual aggression, alcohol use and witnessing violence within the home, the use of violent pornography was associated with significantly higher odds of sexual aggression (Ybarra, Mitchell, Hamburger, Diener-West, \& Leaf, 2011). Findings from a 2009 longitudinal study found that engagement with mainstream pornography, defined as X-rated movies, in early adolescence predicted sexual harassment perpetration among American late adolescent males (Brown \& L'Engle, 2009). More recently, Tomaszewska and Krahe (2018) found that consensual pornography use, defined as "sex photos, presentations of sexual intercourse, presentations of other sexual acts, for example, oral sex, masturbation, and films in which the man and the woman engaged in sexual activities that they both wanted", indirectly predicted sexual aggression by reinforcing attitudes supportive of sexual coercion.

A recent meta-analysis of cross-sectional and longitudinal data identified a small to moderate effect $(r=.28)$ relationship between pornography use and sexual violence (Wright, Tokunaga \& Kraus, 2016). However, individual characteristics and specific content have been found to moderate the strength of the association (Hald, Malamuth \& Yuen, 2010; Malamuth, Addison \& Koss, 2000; Malamuth, Hald \& Koss, 2012; Vega \& Malamuth, 2007; Wright, 2011). Wright et al. (2016) identified a larger effect among those who watched violent pornography ( $r=$ .37 , than those who reported non-violent pornography use $(r=.26)$. 


\section{The Role of Personality Characteristics and Peer Pressure}

More recently, researchers have begun to consider the link between pornography and sexual aggression within a wider context, being influenced by a number of pre-disposing factors, like hostile masculinity (Hunter, Figueredo, \& Malamuth, 2010), callousness (Abbey \& McAuslan, 2004), delinquency and bullying behaviours (Espelage, Basile, De La Rue, \& Hamburger, 2015). These personality traits and individual differences have been suggested as a potentially more important predictor of sexual aggression than pornography use. The confluence

model, an influential conceptualization within this field, emphasises the importance of such traits for sexual violence perpetration (Malamuth, 2018). Personality traits are likely to influence individual behaviour more strongly than peers or pornography use. A predisposition to sexual aggressiveness accounts for a greater part of variance in sexual aggression than pornography use (Vega \& Malamuth, 2007).

Several studies show that psychopathic traits, including low empathy, non-sexual delinquency (Abbey \& McAuslan, 2004) and callousness are important factors in predicting future sexual aggression among adults. Ybarra and Thompson (2018) found that low levels of empathy were more common among perpetrators than non-perpetrators of sexual violence. Delinquent behaviour is linked to increased odds of sexual harassment perpetration. Bullying, which involves intentionally frightening, causing distress or harm to another person (Olweus, 1993) has been shown to predict future sexual harassment perpetration (Espelage et al., 2015), which often precedes other types of sexual violence (see Ybarra \& Thompson, 2018). Such antisocial behaviour is more commonly seen among adolescents who lack empathy. Findings from a number of international studies suggest that callous unemotional and nonempathic traits are related to aggressive behaviour in adolescents across cultures (Essau, Sasagawa, \& Frick, 2006; Fanti, Frick, \& Georgiou, 2009), and that the capacity for interpersonal 
empathy is a protective factor against sexual violence perpetration (Broidy et al., 2003). Callousness, a key indicator of psychopathy, is usually defined as the tendency to use others for personal gain without empathy or feeling bad about it (Frick \& Dickens, 2006). Callousness has been found to predict sexual aggression and delinquent behaviour in adolescent males (Netland \& Miner, 2012). It has been shown to contribute to aggression in two ways: through reactive aggression, which is a result of feeling threatened, and proactive aggression (violence is used to establish dominance)(Price \& Dodge, 1989).

The latter type of aggressiveness may be related to peer pressure and/or striving for peer popularity. Peer pressure and peer conformity in general have been found to significantly predict sexual aggression among young men (Robinson, 2005). Peer groups can influence the likelihood of sexually aggressive behaviour either by increasing pressure for peer group members to have sex (Jacques-Tiura, Abbey, Wegner, Pierce, Pegram \& Woerner, 2015) or by increasing the acceptance of norms that justify forcing a women to have sex (Robinson, 2005). Several studies have shown that conversations within male peer groups about current and hypothetical dating scenarios allow for young men to test and clarify their shared norms and also help them to acquire information about acceptable sexual behaviour (Christopher \& Kisler, 2004; Jacques-Tiura et al., 2015).

\section{Current Study}

The aim of this study was to provide robust and precise (i.e., individual level-based) longitudinal insights about the often hypothesized link between pornography use and sexual aggression. Given the paucity of longitudinal explorations of the topic in adolescents, and the related lack of insights about possible developmental aspects of the key association, no specific hypotheses were formulated. Instead, we focused on the following two research question: (Q1) Is pornography use during middle to late adolescence related to male adolescents' self-reported 
sexual aggressiveness; and, in the case the association is significant, (Q2) whether controlling for personality traits and characteristics that have been associated with sexual aggression affects its significance? The relevance of this study's findings is highlighted by the recent increase in societal concerns regarding pornography use among young people (Stanley et al., 2018; Ybarra \& Thompson, 2018), as well as by the imperative to further improve sexual violence prevention programs (De Koker, Mathews, Zuch, Bastien, \& Mason-Jones, 2014; Lundgren \& Amin, 2015). In addition, our insights may inform pornography literacy programs, which have been recently proposed and developed to help adolescents in navigating the increasingly sexually explicit online environment (Rothman et al., 2018; Vandenbosch \& van Oosten, 2017; Dawson, Nic Gabhainn, \& MacNeela, 2019).

\section{METHOD}

\section{Participants}

The study uses data from a longitudinal study of Croatian adolescents' use of sexualized media described in detail elsewhere (Kohut \& Štulhofer, 2018; Matković, Cohen, \& Štulhofer, 2018). A panel sample of high-school sophomores, aged $15.8(\mathrm{SD}=.52)$ years at baseline, was recruited from 14 larger secondary schools in Rijeka, the third largest city in Croatia. The selected schools represented $63 \%$ of the respective student population. Baseline survey (T1; $n=$ 1,307) was carried out in December 2015. It was repeated in April 2016 (T2; $n=1,309)$, October 2016 (T3; $n=1,252)$, March, 2017 (T4; $n=1202)$, October 2017 (T5; $\mathrm{n}=944)$, and March 2018 (T6; $n=924)$. A notable reduction of the panel sample size at T5 reflected the fact that students who attended 3-year vocational school programs completed their education and left school prior to $\mathrm{T} 5$. Overall, $20 \%$ of male students participated in a single wave only, $11 \%$ in any two waves, $14 \%$ in three, $16 \%$ in four, $19.5 \%$ in five, and $20 \%$ in all six study waves. During data cleaning, a small number of questionnaires $(<30$ per wave) were excluded for substantial inconsistencies or 
humorous responses. In this study, we used data from 594 male students $(M=15.9(\mathrm{SD}=.54)$ who provided information about their sexual aggressiveness.

Attrition was related to school absenteeism (due to illness, educational field trips and outof-school courses, as well as truancy) and difficulties in linking questionnaires across study waves (from T2 to T6, about one questionnaire per class was impossible to link). To explore possible attrition bias, a multivariate logistic regression analysis was carried out with students who participated in all 6 study waves (coded 0 ) and their peers who did not participate in all study waves (coded 1) representing dichotomous dependent variable. Independent variables were key indicators in this study: self-reported sexual aggressiveness, bullying, delinquency, callousness, impulsivity, and pornography use - all measured at T2. No significant betweengroups differences were observed.

\section{Procedure}

Classroom-based self-administered paper and pencil survey was used to collect data. To maximize confidentiality, large screens were placed on school desks to separate participants. Informed consent information was printed on the first questionnaire page, but also delivered by a research assistant who visited all participating schools. In addition, contact information for a national youth psychological health centre was provided at the end of the questionnaire. On average, completion time was between 20-25 minutes. Following national guidelines for ethical research in minors, all parents were sent a leaflet with basic information about the research project prior to the study launch. Ethical Research Committee of the University of Zagreb approved all study procedures.

\section{Measures}

Self-Reported Sexual Aggressiveness. Following Ybarra et al. (2011), at each study wave participants were asked how many times have they "kissed, touched, or done anything sexual 
with another person when that person did not want you to do so." Timeframe for this general indicator of sexually aggressive behaviour was specified as "ever" at T1 and "in the past 6 months" at all subsequent waves. A 3 -point scale $(0=$ never, $1=$ once, $2=$ more than one time $)$ was used to record responses. To address the validity of this self-reported measure, which had satisfactory test-retest reliability (Spearman rank-order correlation coefficients ranged from .21 to .55), we correlated sexual aggressiveness with social desirability (measured by a short 11-item version of the Marlowe-Crowne Social Desirability scale; Reynolds, 1982) at T2 and T4. The findings $\left(r h o_{\mathrm{T} 2}=-.08, p=.083 ; r h o_{\mathrm{T} 4}=-.08, p=.143\right)$ suggested that underreporting was unlikely substantial. Stability coefficients for the indicator ranged from .21 to .55 .

Pornography Use. To assess the frequency of pornography use (which was defined in the questionnaire as any material which openly depicts sexual activity; material which shows naked bodies but not sexual intercourse or other sexual activity does not belong to pornography as here defined) participants were asked the following question at each study wave: "How often have you used pornography during the last 6 months?" Response options ranged from $1=$ not once to $8=$ several times a day. The indicator had high stability across study waves $(r=.58-.83)$. Age at first pornography use/exposure was assessed by the following questions: "How old were you when you first saw, accidentally or deliberately, a pornographic video or movie?"

Four time-invariant controls, assessed at T2, included composite measures of bullying and delinquency as indicators of deviant behaviour, as well as impulsiveness and callousness—which were treated as markers of possible psychopathy. Bullying was assessed by four items ("In the past 12 months, how often did you: (1) Made a rude or nasty comment about someone on online social networks; (2) Used the Internet to embarrass someone; (3) Threatened to hurt someone; and (4) Shoved, slapped or hit someone?") and a 4-point scale for anchoring answers (1 = never, $2=$ once, $3=$ twice, $4=$ three or more times). Cronbach's $\alpha$ for the composite scale was .61 . 
Delinquency was indicated by four items ("I was sent to the headmaster or school psychologist for bad behaviour", "I’ve stayed out all night without my parents' permission", "I stole something", and "I've purposely damaged or destroyed someone's property") adapted from Ybarra \& Mitchell (2004) and Kjellgren et al. (2010). Again, the 4-point scale ranging from $1=$ never to $4=$ three of more times was used to record answers. Cronbach's $\alpha$ for the scale was .67). Impulsiveness was measured with an adapted 8-item (e.g., "I do things without thinking", "I act on the spur of the moment" and "I am self-controlled" /reverse coded/) version of the Barratt Impulsiveness Scale-Brief (Steinberg, Sharp, Stanford, \& Tharp, 2013). Responses were collected on a 4 -item scale ranging from $1=$ never or rarely to $4=$ almost always or always. The composite scale had acceptable internal consistency (Cronbach's $\alpha=.75$ ). Callousness was indicated by four items ("I do not care who I hurt to get what I want", "I do not feel remorseful when I do something wrong", "Feelings of others are unimportant to me", and "I do not care if I get into trouble") with the highest loadings on callousness factor from the adolescent Inventory of Callous-Unemotional Traits (Essau et al., 2006). Response options ranged from $1=$ it does not relate to me at all to $5=$ it relates to me completely. The aggregated scale had satisfactory internal consistency (Cronbach's $\alpha=.78$ ); higher scores indicate higher callousness.

Finally, peer pressure and popularity, which was assessed only at T1, was a composite indicator that included ten items adapted from the Peer Pressure (e.g., "I often feel pressured to do things I wouldn't normally do" and "At times, I've broken rules because others have urged me to") and the Peer Popularity subscales (e.g., "At times, I've ignored some people in order to be more popular with others" and "I often do things just to be popular with people at school") of the the Peer Pressure, Popularity, and Conformity measure developed by Santor, Messervey, and Kusumakar (2000) in a sample of early adolescents. Responses were recorded on a Likert-type scale ranging from $1=$ "does not relate to me at all" to $5=$ "relates to me completely". The 
summed variable had good reliability (Cronbach's $\alpha=.82$ ); higher scores denote higher peer conformism.

\section{Analytical Strategy}

To distinguish between groups of individuals characterized by specific dynamics of selfreported sexual aggressiveness between, approximately, the ages of 16 and 18 years, we used latent class growth modelling (LCGM; Nagin, 1999). Instead of (unrealistically) treating all participants as sharing the same growth trajectory, LCGM enables the estimation of parameters across unobserved subpopulations and the identification of two or more groups of individuals characterized by a distinct latent growth trajectory (Grimm, Ram, \& Estabrook, 2017). Due to the fact that the population heterogeneity is unknown, the number of subpopulations (latent classes) needs to be specified by the researcher. Thus, a number of models with different number of latent classes are estimated and their fit and interpretability compared. In the absence of commonly accepted procedures for choosing the model with correct number of latent classes, we followed recent recommendations (Grimm et al., 2017; Nagin \& Odgers, 2010; Nylund, Asparouhov, \& Muthén, 2007) and used log-likelihood, AIC and BIC values, together with interpretability of group-specific growth trajectories, as the criteria for identifying the best fitting model. The analyses were carried out using the lcmm package (Proust-Lima, Philipps, \& Liquet, 2017) in R. Due to the fact that LCGM can converge to local minima, each analysis was run multiple times with different (randomized) starting values to increase the probability of reaching a global minimum. All available study waves (T1-T6) were used to estimate latent classes in sexual aggressiveness.

To assess change in male adolescents' pornography use in the observed period, we employed latent growth curve modelling (LGM) — a structural equation modelling approach that enables estimation of both between- and within-individual trajectories of change (Little, 2013). 
Although pornography use was measured in all waves (T1-T6), only data from T2-T6 were used in LGM due to the fact that four of the five controls were assessed at T2. As recommended (McArdle \& Grimm, 2010), we first compared a linear and a non-specified cumulative (the first slope loading is fixed to 0 and the last to 1; Preacher, Wicham, MacCallum, \& Briggs, 2008) growth curves in pornography use. The standard chi-square test indicated that the more parsimonious (linear) model should be retained; it fit data equally well as the cumulative curve model $\left(\Delta \chi^{2}=3.10, \Delta \mathrm{df}=3\right)$. Next, we explored an unconditional multi-group LG model of pornography, with latent classes as groups to be compared. Finally, a conditional model, with the four control variables included, was tested. To assess LG models' fit we inspected $\chi^{2}, \mathrm{CFI}$, and RMSEA statistics. Following (Byrne, 2010), TLI and CFI values $\geq .95$ and RMSEA values $\leq .05$ represented good fit to data (RMSEA values $\leq .08$ were taken to indicate acceptable fit). LGCM was carried out using AMOS 24 statistical software package (Arbuckle, 2016).

Finally, to address possible associations between latent classes of sexual aggressiveness and their pornography use over time, we explored a multi-group LG model with latent classes as groups. To control for potential confounders (i.e., personality characteristics that have been found associated with sexual aggressiveness and pornography use; see Baer, Kohut, \& Fisher, 2015; Peter \& Valkenburg, 2016), the multi-group assessment was carried out in a conditional LG model. It should be noted that each of the selected controls (i.e., bullying, delinquency, callousness, impulsiveness, and peer popularity) is characterized by plausible mechanisms of contributing to both pornography use and sexual aggressiveness. For example, a participant's delinquent behaviour may be an outcome of befriending norm-breaking peers who are also more likely to use pornography and sexually coerce than other adolescents. Similarly, striving for peer popularity might contribute to pornography use and sexual aggression if one's peer group is affirmative of both. However, to address concerns over potentially adverse effects of control 
variables on the estimation of key associations (Becker et al., 2016; Carlson \& Wu, 2012), as well as dilemmas about whether some of the select controls could perhaps be outcomes, rather than confounders, the multi-group analysis was also carried out without controls.

After controlling for attrition, less than $2 \%$ of information was missing in the variables of interest. Full information maximum likelihood estimation was used to deal with missing data (Graham, 2012).

\section{RESULTS}

\section{Sexual Aggressiveness Latent Classes}

The LCGM analysis compared models with the number of latent classes ranging from 1 to 6. The model with four latent classes displayed the best fit to the data (Figure 1). Its classification accuracy was high, with posterior classification ranging from $92 \%$ to $99 \%$. The model distinguished among male adolescents who reported marginal levels of sexual aggressiveness, which further decreased over time (latent class $1, n=493: M_{\text {intercept }}=1.04, p=.000 ; M_{\text {slope }}=-.02, p$ $=.043$ ), those characterized by no aggressiveness at baseline followed by a strong growth during the observed period (latent class $2, n=20: M_{\text {intercept }}=.85, p=.000 ; M_{\text {slope }}=.69, p=.000$ ), adolescents who reported moderate sexual aggressiveness at baseline, which then decreased over time (latent class 3, $\mathrm{n}=69: M_{\text {intercept }}=2.00, p=.000 ; M_{\text {slope }}=-.53, p=.000$ ), and the final group of participants who reported stable moderate to high levels of sexual aggressiveness (latent class $4, n$ $\left.=12: M_{\text {intercept }}=2.25, p=.000 ; M_{\text {slope }}=.01, p=.860\right)$.

Due to the fact that three of the four latent classes were small, which presented substantial difficulties for multi-group latent growth analysis, the two latent classes characterized by varying levels of sexual aggressiveness (classes 2 and 3) were collapsed into one. To address the validity of this reduced 3-class model — in which classes were relabelled into A (class 1), B (merged classes 2 and 3) and C (class 4) - a set of one-way ANOVAs were carried out with the key 
indicators explored in this study as dependent variable and latent classes membership as independent variable. All personality characteristics differed significantly between the latent classes. As expected, mean values of bullying, delinquency, callousness, impulsivity and peer pressure/popularity were the lowest in class A and the highest in class C. After applying Bonferroni adjustment for multiple comparisons, mean differences in callousness and impulsivity ceased to be significant (Table 1). Differences in the frequency of pornography use were significant only at baseline (T2), with the highest use reported by class B (moderate and unstable sexual aggressiveness) and the lowest use reported by class A (no or marginal sexual aggressiveness).

FIGURE 1 AND TABLE 1 ABOUT HERE

\section{Sexual Aggressiveness and Pornography Use}

Unconditional 5-wave LG curve model of male adolescents' pornography use had excellent fit: $\chi^{2}(14)=28.95, \mathrm{TLI}=.985, \mathrm{CFI}=.986, \mathrm{RMSEA}=.042[95 \% \mathrm{CI}=.020-.064]$. Although no significant mean growth in pornography use was observed $\left(M_{\text {slope }}=.01, p=.150\right)$, there was significant individual variation around it to warrant the model's growth component $($ var. $=.01, p=.000)$.

Next, we tested a conditional model, in which five individual characteristics were included as predictors of latent baseline and subsequent change in pornography use (Table 2). The model fit the data very well: $\chi^{2}(29)=57.21, \mathrm{TLI}=.965, \mathrm{CFI}=.981, \mathrm{RMSEA}=.040[95 \% \mathrm{CI}$ $=.025-.056]$. As presented in Figure 2, only bullying and peer pressure and popularity significantly predicted baseline levels of pornography use $(\beta=.17$, S.E. $=.04, p=.003$ and $\beta=$ 14 , S.E. $=.15, p=.007$, respectively). More frequent bullying and higher peer pressure and 
popularity scores corresponded to higher pornography use. None of the included characteristics significantly predicted change in pornography use over time.

\section{TABLE 2 AND FIGURE 2 ABOUT HERE}

Finally, to test the association between sexual aggressiveness and pornography use, a multi-group LG curve model was carried out with classes as groups. To control for possible confounding, the conditional model was explored with structural paths leading from personality characteristics to latent intercept and slope in pornography use constrained to equality across groups. Due to the fact that the estimation failed to converge for the smallest group (latent class C, $n=12$ ), only the first two latent classes were compared.

The multi-group model has good fit to the data: $\chi^{2}(69)=121.29, \mathrm{TLI}=.942, \mathrm{CFI}=.964$, RMSEA $=.036[95 \% \mathrm{CI}=.025-.047]$. As presented in Table 3, latent classes A and B differed in baseline levels of pornography use - its frequency being higher in the group that reported higher, albeit inconsistent, sexual aggressiveness. To explore if the difference is statistically significant, we used a likelihood ratio test for nested models to compare the basic model with the one in which the mean intercept of pornography use was constrained to equality. The comparison ( $\Delta \chi^{2}=$ $17.35, \Delta \mathrm{df}=1, p=.000)$ confirmed that the difference was substantial. On average, no significant change in pornography use over time was observed in either latent class.

Omitting the control variables from the analysis affected the findings, in that the average change in pornography use becoming statistically significant in both latent classes. While pornography use slightly increased among male adolescents who reported marginal levels of or no sexual aggression $(M=0.01, \mathrm{SE}=0.01, p=.017)$, in their peers who reported moderate and inconsistent levels of sexual aggression pornography use, on average, decreased over time ( $M=$ - 
$0.03, \mathrm{SE}=0.01, p=.008)$. This finding goes against the notion that pornography use contributed to participants' sexual aggressiveness.

\section{TABLE 3 ABOUT HERE}

\section{DISCUSSION}

Almost 40 year-old concerns about the role of pornography use in sexual violence (Linz, Donnerstein, \& Penrod, 1987) have recently been revived as a reaction to the unprecedented availability of online pornography. The rising prevalence of pornography use among young people - most Croatian men, for example, start watching pornography during adolescence (Sinković, Štulhofer, \& Božić, 2013)—prompted questions about the effects of pornography on sexual socialization, including young people's understanding of non-consensual sex (Bryant, 2009). For many, sexually aggressive traits also first manifest during adolescence, yet the majority of research in this area focuses on the experiences of adults. Understanding the origins of a possible link between sexually explicit media consumption and sexual aggression can help to develop interventions aiming to inoculate young people against the acquisition of sexually aggressive scripts (Wright, 2011).

Given the lack of longitudinal examinations of the link between adolescents' pornography use and sexual aggressiveness, the aim of our study was to analyse it using data from a 6-wave panel sample of male Croatian adolescents. Using LCG and conditional LG modelling, two research questions were explored. According to the findings, the answer to the first question-Is pornography use during middle to late adolescence associated with male adolescents' selfreported sexual aggressiveness? - is dependent of whether the analysis is controlled for potential confounders. With control variables included, we observed no significant association between the 
change in pornography use and the pattern of sexual aggressiveness over time. However, there was a substantial difference in baseline frequency of pornography use between participants who reported little or no sexual aggressiveness and their peers who reported substantial sexual aggressiveness in the period under observation. The former group was characterized by significantly lower initial levels of pornography use than the latter group.

With the controls omitted from the analysis, we observed a significant change in pornography use over time in both latent classes. While a slight increase was observed in adolescents who reported no or marginal levels of sexual aggression, those who reported substantial, although not consistent, sexual aggressiveness were characterized by a decrease in the frequency of pornography use. When considered together with the findings obtained with the controls included, these results do not corroborate a positive dynamic association between male adolescents' pornography use and sexual aggressiveness.

The answer to our second research question (Can individual characteristics account for the association?) is more straightforward. Both of the key constructs were significantly associated with the selected personality characteristics. The frequency of bullying and reported peer pressure and striving for peer popularity were significantly associated with both constructs. An aggressive trait, bullying seems to be logically connected to aggressive sexual behaviour. Studies have shown that bullying predicts sexual violence perpetration in some middle to late adolescent males (Espelage, Basile, Leemis, Hipp, \& Davis, 2018). It has also been shown that both sexual assault (Anderson, Cooper, \& Okamura, 1997; Malamuth, 1986) and bullying are dominance-oriented strategic behaviours (Olthof, Goossens, Vermande, Aleva, \& van der Meulen, 2011). Young men who have internalised beliefs about hegemonic masculinity, characterized by being powerful and dominant, and who see aggression as a tool for social dominance may be more likely to respond with aggression to assert or prove their manhood (Eisler, 1995). 
The role of peer pressure and popularity points to the importance of male peer group dynamics for the understanding of both pornography use and sexual aggressiveness. Social contexts within a peer group around the acceptability of pornography and importance of sexual experiences may be one of the motivating factors for those who consume greater amounts of pornography or behave in a sexually aggressive way. This may particularly be the case in early to middle adolescence, a period in which the desire to be popular peaks (LaFontana \& Cillessen, 2010). Friends' attitudes and behaviour have regularly been identified as risk factors for sexual aggression among young men (Jacques-Tiura et al., 2015; Schwartz, DeKeseredy, Tait, \& Alvi, 2001). Sexually aggressive young adult men report feeling more pressure to have sex than nonsexually aggressive men (Franklin, Bouffard, \& Pratt, 2012), and are more likely to report greater peer acceptance of sexual aggression (Strang \& Peterson, 2013). Peer pressure is often enmeshed with peer selection, because more aggressive adolescents will gravitate towards peers who hold more positive attitudes toward aggressiveness. Through shared experiences and group conformity, these individuals may have their beliefs reinforced and behaviours rewarded (Fehr, 1996).

Vanden Abeele and collaborators found that adolescent men who experienced greater perceived peer pressure and greater need to be popular with peers were also more likely to have pornographic content on their mobile phones (Vanden Abeele, Campbell, Eggermont, \& Roe, 2014). What remains unstudied is whether more frequent pornography use also predicts higher peer popularity. One of the ways in which pornography may facilitate greater peer acceptance is by projecting an image of hyper-masculinity to male (Bond, 2011) and female peers (Wallmyr \& Welin, 2006). Adolescent men who watch more pornography may also exhibit greater variety in knowledge of sexual practices, a characteristic that has been found to be valued among males (Marston \& King, 2006). 
The association between baseline levels of pornography use and sexual aggressiveness was independent of the selected individual characteristics. The observed link indicates that a relation between the two behaviours in an earlier developmental period, during the transition from early to middle adolescence, cannot be ruled out. Younger adolescents might be more susceptible to acquiring information about sex and applying it in their own lives than older adolescents. Early adolescence is particularly important in the context of youth sexual development, because it is characterized by a rising interest in relationships and sexuality, as well as by first experiences with pornography. For example, the latest national probability-based study of emerging Croatian adults aged 18-25 years found that the average age at first pornography use was 11.5 years among male and 13.5 years among female participants (Sinković et al., 2013). Considering that most early adolescents have no sexual experience with another person, pornographic imagery and scripting may be more influential in this developmental phase compared to middle or late adolescence. In contrast to early adolescent boys, older adolescents can weigh pornographic material against real sexual experiences. Based on appropriate conceptualization, future studies should also address a possible moderating role of these constructs.

\section{Study Strengths and Limitations}

Compared to the existing literature, this study has several strengths, including withinindividual longitudinal assessment of both key constructs, a relatively lengthy observation period and well-powered analyses. In addition, our analysis of the target association controlled for a number of potential confounders discussed in previous studies, which adds credibility to our insights. Nevertheless, the conclusions should be weighed against a couple of limitations. First, sexual aggressiveness was represented by a single-item indicator. Although the item had reasonable construct validity and test-retest reliability, the fact that it covered a very broad range 
of coercive erotic/sexual acts made impossible to explore developmental trajectories of sexual aggressiveness (e.g., is there an increase in the severity of coercive acts over time?) in the period of middle to late adolescence.

Our decision to use a single item measure of pornography use is consistent with the literature suggesting that single-item indicators should be used when the measured construct and its attributes are easily and uniformly understood (Bergkvist \& Rossiter, 2007; Diamantopoulos, Sarstedt, Fuchs, Wilczynski, \& Kaiser, 2012). This approach, however, raises questions around the content of pornography that our participants engaged with. Although it appears that violent/aggressive pornography is not very common among adolescents (see, Landripet, Buško \& Štulhofer, 2019), important differences have been found between those who watch pornography depicting consensual and non-consensual encounters (Ybarra et al., 2011; Tomaszewska and Krahe, 2018). Future research should distinguish between consensual and non-consensual sexually explicit content when addressing the link between young people's pornography use and sexual aggressiveness.

A second limitation pertains to the fact that the most relevant group of participants (i.e., those who consistently reported high sexual aggressiveness) for this study's topic was too small for meaningful multivariate analysis. Taking into account that this group is likely similarly slight in the respective population, difficulties with statistical power behind estimations involving highly sexually aggressive adolescents will likely continue to hamper research in this area.

\section{CONCLUSIONS}

One of the few longitudinal studies that focused on possible linkage between pornography use and sexual aggressiveness in adolescence, this study adds to the existing knowledge about this highly socially relevant topic. Taking into account the need to prevent or at least reduce sexual coercion among young people, the significant association between pornography use and 
self-reported sexual aggressiveness at the age of 16-17 years suggests that school-based sexual violence prevention programs should commence in an early developmental period and address, among other things, the potentially contributing role of pornography use in the development of sexual aggressiveness. Similarly, our findings may inform recently proposed pornography literacy programs (Dawson, Nic Gabhainn \& MacNeela, 2019), which were meant to provide tools for critical interpretation of sexually explicit imagery, but also to educate that "lack of consent is never acceptable, and that healthy relationships do not feature coercion or violence" (Rothman et al., 2018: 4). Pornography seems to play a complex role in contemporary adolescents' lives (Löfgren-Mårtenson \& Månsson, 2010) and this calls for systematic research and educational interventions (Dawson, Nic Gabhainn \& MacNeela, 2019). 


\section{REFERENCES}

Abbey, A., \& McAuslan, P. (2004). A longitudinal examination of male college students' perpetration of sexual assault. Journal of Consulting and Clinical Psychology, 72(5), 747-756. https://doi.org/10.1037/0022-006X.72.5.747

Anderson, K. B., Cooper, H., \& Okamura, L. (1997). Individual differences and attitudes toward rape: A meta-analytic review. Personality and Social Psychology Bulletin, 23(3), 295-315. https://doi.org/10.1177/0146167297233008

Arbuckle, J. L. (2016). IBM AMOS 24 User's Guide. Amos Development Corporation. Retrieved from

ftp://public.dhe.ibm.com/software/analytics/spss/documentation/statistics/24.0/en/amos/Man uals/IBM_SPSS_Amos_User_Guide.pdf

Baer, J. L., Kohut, T., \& Fisher, W. A. (2015). Is pornography use associated with anti-woman sexual aggression? Re-examining the Confluence Model with third variable considerations. Canadian Journal of Human Sexuality, 24(2), 160-173. https://doi.org/10.3138/cjhs.242-A6

Bandura, A. (1978). Social learning theory of aggression. Journal of Communication, 28(3), 12-29. https://doi.org/10.1111/j.1460-2466.1978.tb01621.x

Becker, T. E., Atinc, G., Breaugh, J. A., Carlson, K. D., Edwards, J. R., \& Spector, P. E. (2016). Statistical control in correlational studies: 10 essential recommendations for organizational researchers. Journal of Organizational Behavior, 37(2), 157-167.

https://doi.org/10.1002/job.2053

Bergkvist, L., \& Rossiter, J. R. (2007). The Predictive Validity of Multiple-Item Versus SingleItem Measures of the Same Constructs. Journal of Marketing Research, 44(2), 175-184. https://doi.org/10.1509/jmkr.44.2.175 
Bond, E. (2011). The mobile phone = bike shed? Children, sex and mobile phones. New Media \& Society, 13(4), 587-604. https://doi.org/10.1177/1461444810377919

Broidy, L. M., Nagin, D. S., Tremblay, R. E., Bates, J. E., Brame, B., Dodge, K. A., ... Vitaro, F. (2003). Developmental trajectories of childhood disruptive behaviors and adolescent delinquency: A six-site, cross-national study. Developmental Psychology, 39(2), 222-245.

Brown, J. D., \& L'Engle, K. L. (2009). X-Rated: Sexual Attitudes and Behaviors Associated With U.S. Early Adolescents' Exposure to Sexually Explicit Media. Communication Research, 36(1), 129-151. https://doi.org/10.1177/0093650208326465

Bryant, C. (2009). Adolescence, pornography and harm. Trends \& issues in crime and criminal justice. Canberra. Retrieved from https://aic.gov.au/publications/tandi/tandi368

Byrne, B. M. (2010). Structural equation modeling with AMOS: Basic concepts, applications, and programming. Routledge (Vol. 22). https://doi.org/10.4324/9781410600219

Carlson, K. D., \& Wu, J. (2012). The ilusion of statistical control: Control variable practice in management research. Organizational Research Methods, 15(3), 413-435. https://doi.org/10.1177/1094428111428817

Christopher, F. S., \& Kisler, T. S. (2004). Sexual aggression in romantic relationships. In J. H. Harvey, A. Wenzel, \& S. Sprecher (Eds.), The Handbook of Sexuality in Close Relationships (pp. 287-309). Mahwah, NJ: Lawrence Erlbaum Associates, Inc.

D’Alessio, D., \& Allen, M. (2007). The Selective Exposure hypothesis and media choice processes. In R. W. Preiss, B. M. Gayle, N. Burrell, M. Allen, \& J. Bryant (Eds.), Mass Media Effects Research: Advances Through Meta-analysis (pp. 103-118). New York: Routledge.

De Koker, P., Mathews, C., Zuch, M., Bastien, S., \& Mason-Jones, A. J. (2014). A systematic review of interventions for preventing adolescent intimate partner violence. Journal of 
Adolescent Health, 54(1), 3-13. https://doi.org/10.1016/j.jadohealth.2013.08.008

Diamantopoulos, A., Sarstedt, M., Fuchs, C., Wilczynski, P., \& Kaiser, S. (2012). Guidelines for choosing between multi-item and single-item scales for construct measurement: A predictive validity perspective. Journal of the Academy of Marketing Science, 40(3), 434-449. https://doi.org/10.1007/s11747-011-0300-3

Eisler, R. M. (1995). The relationship between masculine gender role stress and men's health risk: The validation of a construct. In R. F. Levant \& W. S. Pollack (Eds.), A New Psychology of Men (pp. 207-225). New York: Basic Books.

Espelage, D. L., Basile, K. C., De La Rue, L., \& Hamburger, M. E. (2015). Longitudinal associations among bullying, homophobic teasing, and seexual violence perpetration among middle school students. Journal of Interpersonal Violence, 30(14), 2541-2561. https://doi.org/10.1177/0886260514553113

Espelage, D. L., Basile, K. C., Leemis, R. W., Hipp, T. N., \& Davis, J. P. (2018). Longitudinal examination of the bullying-sexual violence pathway across early to late adolescence: Implicating homophobic name-calling. Journal of Youth and Adolescence, 47(9), 1880-1893. https://doi.org/10.1007/s10964-018-0827-4

Essau, C. A., Sasagawa, S., \& Frick, P. J. (2006). Callous-unemotional traits in a community sample of adolescents. Assessment, 13(4), 454-469. https://doi.org/10.1177/1073191106287354

Fanti, K. A., Frick, P. J., \& Georgiou, S. (2009). Linking callous-unemotional traits to instrumental and non-instrumental forms of aggression. Journal of Psychopathology and Behavioral Assessment, 31(4), 285-298. https://doi.org/10.1007/s10862-008-9111-3

Fehr, B. (1996). Friendship Processes. Thousand Oaks, CA: Sage.

Fortenberry, J. D. (2014). Puberty and adolescent sexuality. Hormones and Behavior, 64(2), 
280-287. https://doi.org/10.1016/j.yhbeh.2013.03.007.Puberty

Franklin, C. A., Bouffard, L. A., \& Pratt, T. C. (2012). Sexual assault on the college campus. Criminal Justice and Behavior, 39(11), 1457-1480.

https://doi.org/10.1177/0093854812456527

Frick, P. J., \& Dickens, C. (2006). Current perspectives on conduct disorder. Current Psychiatry Reports, 8(1), 59-72.

Graham, J. W. (2012). Missing Data: Analysis and Design. New York: Springer. https://doi.org/10.1007/978-1-4614-4018-5

Grimm, K. J., Ram, N., \& Estabrook, R. (2017). Growth Modeling: Structural Equation and Multilevel Modeling Approaches. New York: Guilford Press.

Hunter, J. A., Figueredo, A. J., \& Malamuth, N. M. (2010). Developmental pathways into social and sexual deviance. Journal of Family Violence, 25(2), 141-148. https://doi.org/10.1007/s10896-009-9277-9

Jacques-Tiura, A. J., Abbey, A., Wegner, R., Pierce, J., Pegram, S. E., \& Woerner, J. (2015). Friends matter: Protective and harmful aspects of male friendships associated with past-year sexual aggression in a community sample of young men. American Journal of Public Health, 105(5), 1001-1007. https://doi.org/10.2105/AJPH.2014.302472

Kjellgren, C., Priebe, G., Svedin, C. G., \& Långström, N. (2010). Sexually coercive behavior in male youth: Population survey of general and specific risk factors. Archives of Sexual Behavior, 39(5), 1161-1169. https://doi.org/10.1007/s10508-009-9572-9

Kohut, T., \& Štulhofer, A. (2018). Is pornography use a risk for adolescent wellbeing? An examination of temporal relationships in two independent panel samples. PLOS ONE, 13(8), e0202048. https://doi.org/10.1371/journal.pone.0202048

LaFontana, K. M., \& Cillessen, A. H. N. (2010). Developmental changes in the priority of 
perceived status in childhood and adolescence. Social Development, 19(1), 130-147. https://doi.org/10.1111/j.1467-9507.2008.00522.x

Linz, D., Donnerstein, E., \& Penrod, S. (1987). The findings and recommendations of the Attorney General's Commission on Pornography: Do the psychological "facts" fit the political fury? American Psychologist, 42(10), 946-953.

Little, T. D. (2013). Longitudinal Structural Equation Modeling. New York: Guilford Press.

Lundgren, R., \& Amin, A. (2015). Addressing intimate partner violence and sexual violence among adolescents: Emerging evidence of effectiveness. Journal of Adolescent Health, 56(1 Suppl), S42-50. https://doi.org/10.1016/j.jadohealth.2014.08.012

Malamuth, N. M. (1986). Predictors of naturalistic sexual aggression. Journal of Personality and Social Psychology, 50(5), 953-962.

Malamuth, N. M. (2018). "Adding fuel to the fire"? Does exposure to non-consenting adult or to child pornography increase risk of sexual aggression? Aggression and Violent Behavior, 41, 74-89. https://doi.org/10.1016/J.AVB.2018.02.013

Marston, C., \& King, E. (2006). Factors that shape young people's sexual behaviour: A systematic review. The Lancet, 368(9547), 1581-1586. https://doi.org/10.1016/S01406736(06)69662-1

Matković, T., Cohen, N., \& Štulhofer, A. (2018). The Use of Sexually Explicit Material and Its Relationship to Adolescent Sexual Activity. Journal of Adolescent Health, 62(5), 563-569. https://doi.org/10.1016/j.jadohealth.2017.11.305

McArdle, J. J., \& Grimm, K. J. (2010). Five steps in latent curve and latent change score modeling with longitudinal data. In K. van Montfort, J. Oud, \& A. Sattora (Eds.), Longitudinal Research with Latent Variables (pp. 245-273). New York: Springer. https://doi.org/10.1007/978-3-642-11760-2_8 
Nagin, D. S. (1999). Analyzing developmental trajectories: A semiparametric, group-based approach. Psychological Methods, 4(2), 139-157. https://doi.org/10.1037/1082989X.4.2.139

Nagin, Daniel S., \& Odgers, C. L. (2010). Group-Based Trajectory Modeling in Clinical Research. Annual Review of Clinical Psychology, 6(1), 109-138. https://doi.org/10.1146/annurev.clinpsy.121208.131413

Netland, J. D., \& Miner, M. H. (2012). Psychopathy traits and parental dysfunction in sexual offending and general delinquent adolescent males. Journal of Sexual Aggression, 18(1), 4-22. https://doi.org/10.1080/13552600.2011.632696

Nylund, K. L., Asparouhov, T., \& Muthén, B. O. (2007). Deciding on the Number of Classes in Latent Class Analysis and Growth Mixture Modeling: A Monte Carlo Simulation Study. Structural Equation Modeling: A Multidisciplinary Journal, 14(4), 535-569. https://doi.org/10.1080/10705510701575396

Olthof, T., Goossens, F. A., Vermande, M. M., Aleva, E. A., \& van der Meulen, M. (2011). Bullying as strategic behavior: Relations with desired and acquired dominance in the peer group. Journal of School Psychology, 49(3), 339-359. https://doi.org/10.1016/j.jsp.2011.03.003

Peter, J., \& Valkenburg, P. M. (2016). Adolescents and pornography: A review of 20 years of research. Journal of Sex Research, 53(4-5), 509-531. https://doi.org/10.1080/00224499.2016.1143441

Preacher, K. J., Wicham, A. L., MacCallum, R. C., Briggs, N. E., Wichman, A. L., MacCallum, R. C., ... Preacher, K. J., Wichman, A. L., MacCallum, R. C., \& Briggs, N. E. (2008). Latent Growth Curve Modeling. Thousand Oaks, CA, CA: Sage.

Price, J. M., \& Dodge, K. A. (1989). Reactive and proactive aggression in childhood: Relations to 
peer status and social context dimensions. Journal of Abnormal Child Psychology, 17(4), 455-471. https://doi.org/10.1007/BF00915038

Proust-Lima, C., Philipps, V., \& Liquet, B. (2017). Estimation of extended mixed models using latent classes and latent processes: The R package lcmm. Journal of Statistical Software, 78(2), 1-56. https://doi.org/10.18637/jss.v078.i02

Reynolds, W. M. (1982). Development of reliable and valid short forms of the Marlowe-Crowne Social Desirability Scale. Journal of Clinical Psychology, 38(1972), 119-125.

Righthand, S., Welch, C., Carpenter, E. M., Young, G. S., \& Scoular, R. J. (2001). Sex offending by Maine youth: Their offenses and characteristics. Retrieved from https://www.maine.gov/dhhs/ocfs/cw/appendixc2.pdf

Robinson, K. H. (2005). Reinforcing hegemonic masculinities through sexual harassment: Issues of identity, power and popularity in secondary schools. Gender and Education, 17(1), 19-37. https://doi.org/10.1080/0954025042000301285

Rothman, E. F., Adhia, A., Christensen, T. T., Paruk, J., Alder, J., \& Daley, N. (2018). A pornography literacy class for youth: Results of a feasibility and efficacy pilot study. American Journal of Sexuality Education, 13(1), 1-17. https://doi.org/10.1080/15546128.2018.1437100

Santor, D. A., Messervey, D., \& Kusumakar, V. (2000). Measuring peer pressure, popularity, and conformity in adolescent boys and girls: Predicting school performance, sexual attitudes, and substance abuse. Journal of Youth and Adolescence, 29(2), 163-182. https://doi.org/10.1023/A:1005152515264

Schwartz, M. D., DeKeseredy, W. S., Tait, D., \& Alvi, S. (2001). Male peer support and a feminist routing activities theory: Understanding sexual assault on the college campus. Justice Quarterly, 18(3), 623-649. https://doi.org/10.1080/07418820100095041 
Simon, W., \& Gagnon, J. H. (2003). Sexual scripts: Origins, influences and changes. Qualitative Sociology, 26(4), 491-497. https://doi.org/10.1023/B:QUAS.0000005053.99846.e5

Sinković, M., Štulhofer, A., \& Božić, J. (2013). Revisiting the association between pornography use and risky sexual behaviors: The role of early exposure to pornography and sexual sensation seeking. Journal of Sex Research, 50(7), 633-641. https://doi.org/10.1080/00224499.2012.681403

Stanley, N., Barter, C., Wood, M., Aghtaie, N., Larkins, C., Lanau, A., \& Överlien, C. (2018). Pornography, sexual coercion and abuse and sexting in young people's intimate relationships: A European study. Journal of Interpersonal Violence, 33(19), 2919-2944. https://doi.org/10.1177/0886260516633204

Steinberg, L., Sharp, C., Stanford, M. S., \& Tharp, A. T. (2013). New tricks for an old measure: The development of the Barratt Impulsiveness Scale-Brief (BIS-Brief). Psychological Assessment, 25(1), 216-226. https://doi.org/10.1037/a0030550

Strang, E., \& Peterson, Z. D. (2013). The relationships among perceived peer acceptance of sexual aggression, punishment certainty, and sexually aggressive behavior. Journal of Interpersonal Violence, 28(18), 3369-3385. https://doi.org/10.1177/0886260513502126

Tomaszewska, P., \& Krahé, B. (2018). Predictors of sexual aggression victimization and perpetration among Polish university students: A longitudinal study. Archives of Sexual Behavior, 47(2), 493-505. https://doi.org/10.1007/s10508-016-0823-2

Vanden Abeele, M., Campbell, S. W., Eggermont, S., \& Roe, K. (2014). Sexting, mobile porn use, and peer group dynamics: Boys' and girls' self-perceived popularity, ned for popularity, and perceived peer pressure. Media Psychology, 17(1), 6-33. https://doi.org/10.1080/15213269.2013.801725

Vandenbosch, L., \& van Oosten, J. M. F. F. (2017). The relationship between online pornography 
and the sexual objectification of women: The attenuating role of porn literacy education. Journal of Communication, 67(6), 1015-1036. https://doi.org/10.1111/jcom.12341

Vega, V., \& Malamuth, N. M. (2007). Predicting sexual aggression: The role of pornography in the context of general and specific risk factors. Aggressive Behavior, 33(2), 104-117. https://doi.org/10.1002/ab.20172

Wallmyr, G., \& Welin, C. (2006). Young people, pornography, and sexuality: Sources and attitudes. Journal of School Nursing, 22(5), 290-295.

https://doi.org/10.1177/10598405060220050801

Wright, P. J., \& Bae, S. (2016). Pornography and male socialization. In Y. J. Wong \& S. R. Wester (Eds.), APA Handbook of Men and Masculinities. (pp. 551-568). Washington, D.C.: American Psychological Association. https://doi.org/10.1037/14594-025

Ybarra, M. L., \& Mitchell, K. J. (2004). Youth engaging in online harassment: Associations with caregiver-child relationships, Internet use, and personal characteristics. Journal of Adolescence, 27(3), 319-336. https://doi.org/10.1016/j.adolescence.2004.03.007

Ybarra, M. L., Mitchell, K. J., Hamburger, M., Diener-West, M., \& Leaf, P. J. (2011). X-rated material and perpetration of sexually aggressive behavior among children and adolescents: Is there a link? Aggressive Behavior, 37(1), 1-18. https://doi.org/10.1002/ab.20367

Ybarra, M. L., \& Thompson, R. E. (2018). Predicting the emergence of sexual violence in adolescence. Prevention Science, 19(4), 403-415. https://doi.org/10.1007/s11121-017-08104 
